\title{
SOIL MICROBIAL DIVERSITY AND ANTIBIOTIC RESISTANCE IN NATURAL AND TRANSFORMED ECOSYSTEMS
}

\author{
Lyudmyla Symochko $^{1 *}$, Hosam E.A.F. Bayoumi Hamuda ${ }^{2}$, Olena Demyanyuk ${ }^{3}$, \\ Vitaliy Symochko ${ }^{1}$, Volodymyr Patyka ${ }^{4}$ \\ ${ }^{1 *}$ Faculty of Biology; SR\&E Center of Molecular Microbiology and the Immunology of Mucous Membranes, \\ Uzhhorod National University, Voloshyna Str. 32, 88000, Uzhhorod, Ukraine; \\ ${ }^{2}$ Institute of Environmental Engineering, Obuda University, H-1034, Doberdo Str.6, Budapest, Hungary; \\ ${ }^{3}$ Institute of Agroecology and Environmental Management NAAS, Metrologichna Str., 12, Kyiv, 03143, Ukraine; \\ ${ }^{4}$ D.K. Zabolotny Institute of Microbiology and Virology, Akad. Zabolotnoho Str, 154, 03680, Kyiv, Ukraine;
}

*Corresponding Author Lyudmyla Symochko, email: lyudmilassem@gmail.com;

Received June 2019; Accepted July 2019; Published September 2019;

DOI: https://doi.org/10.31407/ijees9323

\begin{abstract}
Terrestrial ecosystems may provide an ideal setting for the acquisition and dissemination of antibiotic resistance, because they are frequently impacted by anthropogenic activities. The soil microbiome plays an important role in development and spread of antibiotic resistance in humans. The aim of our study was to detect the antibiotic resistance soil bacteria in different ecosystems: natural ecosystems, agroecosystems and urboecosystems. Were isolated 468 dominanting bacteria, among them 79 antibiotic resistant bacteria. All isolates were multi-drug resistant, of which greater than 74,5\% were resistant to 9 antibiotics. A study of soil samples from the primeval forests showed that the microbial community characterized by a low content of antibiotic-resistant microorganisms. Among 78 isolated bacteria only two of them Bacillus cereus, and Pantoea agglomerans demonstrated high level of resistance to antibiotics. A total 106 strains were isolated from the soil of medicinal plants, 13 of them were antibiotic-resistant. The greatest numbers of antibiotic-resistant bacteria have been isolated from soil of urboecosystems and agroecosystems contaminated by enrofloxacin. Among the 284 tested bacteria 64 were antibiotic resistant. Multi-resistance were such pathogenic and conditionally pathogenic bacteria as: Enterococcus faecium, Acinetobacter baumannii, Pseudomonas aeruginosa, Escherichia coli, Bacillus licheniformis, Serratia fonticola, Hafnia alvei, Bacillus cereus, Bacillus megaterium and Clostridium difficile.
\end{abstract}

Keywords: ecosystem, soil, diversity, microbiome, antibiotic resistance. 